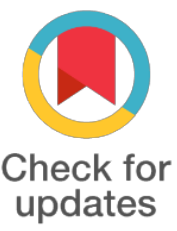

${ }^{*}$ For correspondence:

thuong.ttd@ump.edu.vn

Competing interests: The authors declare that no competing interests exist.

Received: 2017-06-27

Accepted: 2017-07-14

Published: 2017-09-05

Copyright The Author(s) 2017. This article is published with open access by BioMedPress (BMP).

This article is distributed under the terms of the Creative Commons Attribution License (CC-BY 4.0) which permits any use, distribution, and reproduction in any medium, provided the original author(s) and the source are credited.

\section{Efficiency of the combination of modified acupuncture and motor relearning method in post-stroke patients}

\author{
Bui Pham Minh Man, Thuong Trinh Thi Dieu \\ University Medical Hospital HCMC \\ 221B Hoang Van Thu, Ho Chi Minh City, Vietnam
}

\section{Abstract}

Background and Objectives: The combination of modern medicine and traditional medicine in the rehabilitation of motor deficit after stroke has shown interesting results. Many studies on modified acupuncture, a combination of modern and traditional techniques, have proven its effectiveness in motor rehabilitation in post-stroke patients. Furthermore, many studies have elucidated the effectiveness of the motor relearning method in the treatment of post-stroke paralysis. Therefore, this study aims to determine whether the combination of modified acupuncture and motor relearning method can improve the treatment results. Method: Multicentered randomized controlled trial (Traditional Medicine Hospital of Ho Chi Minh City, General Hospital of Soc Trang Province, and People Military Hospital of Soc Trang Province) from July 2014 to July 2015. 66 post-stroke patients were divided into two groups: a control group received modified acupuncture combined with Bobath method and a trial group received modified acupuncture combined with motor relearning method. After six weeks, patients were evaluated according to the Barthel score, 10-hole test, and 10-meter-walk test. Results: The trial group showed better results than the control group did. There was a significant difference between two groups in Barthel score and 10-meter-walk test, but not in the 10-hole test. After treatment, $77.42 \%$ patients of the trial group showed improvement while only there are $51.61 \%$ in the other group $(P<0.05)$. Conclusion: The combination of modified acupuncture and motor relearning method is more effective than the combination of modified acupuncture and Bobath method in the rehabilitation of motor deficit after stroke.

\section{Keywords}

Modified acupuncture; Motor relearning; Barthel score; 10-hole test; 10-meter-walk test.

Funding

References 